\title{
Korsibiomassojen laatu bioetanolin raaka-aineena
}

\author{
Katri Pahkala ja Markku Kontturi \\ MTT Kasvintuotannon tutkimus, E-talo, 31600 Jokioinen, etunimi.sukunimi@mtt.fi
}

\section{Tiivistelmä}

Nykyisin Suomessa viljeltyä ruokohelpeä käytetään teollisesti lähinnä sähkön ja lämmön tuottamiseksi. Tällöin biomassan korjuu ajoitetaan huhti-toukokuulle. Ohra pyritään puimaan rehu- ja elintarvikelaadun kannalta parhaaseen ajankohtaan eli Suomessa elokuun keskivaiheilla. Koska lignoselluloosapohjaisen bioetanolivalmistuksen kannalta nämä korjuuajankohdat eivät välttämättä ole kaikkein optimaalisimmat, tutkimme AGROETA-projektissa sadonkorjuuajankohdan merkitystä raakaaineen koostumukselle. Bioetanolituoton kannalta maksimoinnin kohteita olivat hiilihydraattien (tärkeimpänä selluloosa) massasaanto per hehtaari, ligniinipitoisuuden ja piipitoisuuden minimointi sekä yleinen tekninen soveltuvuus bioetanoliprosessiin.

Ruokohelven suurin kuiva-ainesato (11 t/ha) saatiin noin kuukausi siemenen kypsymisen jälkeen. Selluloosan suhteellinen osuus sadossa lisääntyi kevääseen saakka. Lokakuun näytteenotosta (kehitysvaihe 7, pitoisuus 44,9 \%) lähtien muutokset selluloosapitoisuudessa eivät kuitenkaan olleet tilastollisesti merkitseviä. Myös hemiselluloosa- ja ligniinipitoisuudet olivat suurempia myöhäissyksyllä ja kevätsadossa kuin aikaisemmissa näytteenotoissa. Vuonna 2003 kylvetyssä kokeessa kevätsadon hemiselluloosapitoisuus vaihteli välillä 25,1 - 28,3 \% ka ja vuonna 1990 kylvetyssä kokeessa välillä 29,5 31,9 \% ka. Tämän vuoksi biomassasadon pieneneminen syksyn ja talven aikana vaikutti vain vähän kuitukomponenttien hehtaarisaantoon. Ruokohelven kevätsato oli ensimmäisenä korjuuvuonna pienempi kuin syyskesällä korjattu sato, mutta sen kuiva-ainepitoisuus oli korkea.

Ohran kasvua ja oljen laadun kehitystä seurattiin vuosina 2005 ja 2006 ottamalla näytteitä tähkälle tulon ja korjuun välillä kuusi kertaa. Kasvuston biomassa kasvoi aina elokuun alkuun asti. Se oli tällöin

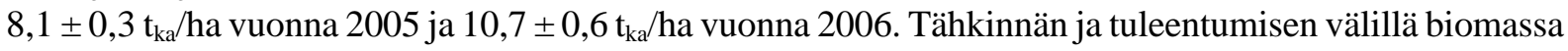
kaksinkertaistui. Kasvu johtui tähkänpainon kasvusta. Vastaavasti olkisato hieman pieneni, kun korteen ennen tähkintää tilapäisesti varastoituneet yhteyttämistuotteet siirtyivät jyviin. Tähkän (jyvät+vihneet+tähkän lapakko) osuus kokonaissadoista oli 64 \% vuonna 2005 ja 69 \% vuonna 2006. Ennen laatuanalyysejä tähkä ja olki erotettiin toisistaan. Oljesta oli selluloosaa, hemiselluloosaa ja ligniiniä noin 48, 25 ja 7 \% vuonna 2005 ja vuonna 2006 vastaavasti noin 44, 25 ja 8 \%. Kahden viimeisen näytteenoton välillä kasvuston hehtaarisato pieneni noin $10 \%$. Tämä johtuu lähinnä kasvuston hengityksestä ja lehtien varisemisesta. Vuonna 2006 oljen kosteus oli keltatuleentuneena 37 \% ja leikkuupuitaessa $21 \%$.

Tässä tutkimuksessa bioetanolin valmistukseen päädyttiin käyttämään siemenvaiheessa ja keväällä korjattua ruokohelpimateriaalia, jotka molemmat olivat prosessoitaessa lähes samanarvoisia. Ohran oljen osalta päädyttiin yhteen korjuuaikaan, joka tapahtuisi normaalin leikkuupuinnin yhteydessä. Tällöin olkea voi ympäristön kannalta käsitellä sivuvirtana.

\section{Avainsanat}

ohra, ruokohelpi, biomassa, sato, olkisato, kuitu, sokeri, bioetanoli 


\section{Johdanto}

Tieliikenteessä käytettäviä biopolttoaineita ovat bensiiniin lisättävä etanoli ja dieseliin lisättävä biodiesel. Biomassoista tuotettua etanolia nimitetään tässä yhteydessä bioetanoliksi. Bioetanolin valmistus ruokosokerista ja viljan jyvien tärkkelyksestä on yleisin tuotantomenetelmä. Prosessi on kuitenkin kallis ja vaatii paljon energiaa. Lisäksi se ei ole optimaalinen kasvihuonekaasutaseiden osalta (Mäkinen et al., 2006). Sakkaroosin ja tärkkelyksen lisäksi bioetanolia voidaan tuottaa selluloosapitoisista raaka-aineista kuten korsibiomassoista ja puusta. Tällöin on kysymys nk. toisen sukupolven bioetanolista. Kaupallisia selluloosapitoisia raaka-aineita käyttäviä bioetanolilaitoksia on rakenteilla Yhdysvalloissa (von Weymarn, 2007). Ruotsissa puuraaka-aineeseen perustuva sellutehtaan yhteyteen rakennettu Domsjö Fabriker -laitos on aloittanut jo toimintansa Örnsködsvikissä.

MTT:n ja VTT:n AGROETA-tutkimuksen tarkoituksena oli arvioida, miten maatalouden korsibiomassoihin pohjautuva bioetanolin tuotantomalli soveltuisi Suomeen (von Weymarn, 2007). Tutkimuskohteina olivat ruokohelpi ja ohran olki. Suomessa ruokohelpeä käytetään teollisesti lähinnä sähkön ja lämmön tuottamiseksi. Tällöin biomassa korjataan huhti/toukokuulla. Ohra pyritään puimaan rehu- ja elintarvikelaadun kannalta parhaaseen ajankohtaan. Suomessa ohran puinti ajoittuu näin ollen normaalisti elokuun keskivaiheille. Lignoselluloosapohjaisen bioetanolin valmistuksen kannalta nämä korjuuajankohdat eivät välttämättä ole kaikkein optimaalisimmat. MTT:n tehtävänä oli tutkia sadonkorjuuajankohdan merkitystä raaka-aineen koostumukseen. Bioetanolituotannon kannalta maksimoinnin kohteita olivat hiilihydraattien (tärkeimpänä selluloosa) massasaanto per hehtaari, ligniinipitoisuuden ja piipitoisuuden minimointi sekä yleinen tekninen soveltuvuus bioetanoliprosessiin.

\section{Aineisto ja menetelmät}

Ruokohelpi

Ruokohelpitutkimukset sijaitsivat Jokioisten kartanoiden pelloilla vuosina 2005-2006. Viimeinen ruokohelpinäyte otettiin keväällä 2007. Kasvustomittaukset (biomassa, korsien ja lehtien määrä) tehtiin MTT:n Kasvintuotannon tutkimuksessa.

Tutkimuksessa käytettiin kahta eri-ikäistä ruokohelpiviljelystä, joista vanhempi oli kylvetty vuonna 1990 (koe 702) ja nuorempi vuonna 2003 (koe 703). Koealueet jaettiin neljään kerranteeseen. Koejäsenten paikat arvottiin kerranteen sisällä eri näytteenottokertoja varten. Kokeessa 702 näytteenottokertoja oli ainoastaan kolme, sillä käytettävissä oleva ala oli pienempi. Tutkimuksessa käytetyn ruokohelpimateriaalin kehitysvaihe eri näytteenottokertoina oli seuraava (näytteenottopäivämäärät on esitetty taulukossa 1$)$ :

Koe 702

1. Siemenen kypsyttyä

2. Siemenen kypsymisestä n.3 kk

3. Seuraavana keväänä kuloheinänä

Koe 703

1. 20 \% kasveista röyhy näkyvissä, kesäkuu

2. Kukinnan alussa

3. Kukinnan lopussa

4. Siemenen kypsyttyä

5. Siemenen kypsymisestä n. 1 kk

6. Siemenen kypsymisestä n. 2 kk

7. Siemenen kypsymisestä n. $3 \mathrm{kk}$

8. Kasvusto kellastunut

9. Seuraavana keväänä kuloheinänä

Näytteet otettiin jokaisesta ruudusta leikkaamalla kasvusto $1 \mathrm{~m}^{2}: \mathrm{n}$ alalta edellä mainituissa kehitysvaiheissa. Osa näytteestä käytettiin kuiva-aineen määrittämiseen. Lehtien ja varsien osuus biomassasta määritettiin $0,25 \mathrm{~m}^{2}$ alalta korjatuista kasveista. Loput kasveista kuivattiin alle $+40{ }^{\circ} \mathrm{C}$ :ssa kemiallisia analyysejä varten.

Vuonna 2005 analysoitiin kaikista näytteistä biomassan määrä, kasvinosien osuudet (lehdet ja korsi mukaan lukien lehtitupet ja kukinnot), kuituosuus (selluloosa, hemiselluloosa, ligniini), liukoiset sokerit (glukoosi, fruktoosi, sakkaroosi, fruktaani, kokonaissokeri). Lisäksi kokeen 702 kevätnäytteistä ja kokeen 703 näytteistä 4, 8 ja 9 mitattiin tuhkapitoisuus ja kivennäisaineita. Vuonna 2006 kaikista näytteistä 
määritettiin biomassan määrä ja kasvinosien osuudet. Lisäksi kokeen 703 näytteistä 4-9 määritettiin kuidut ja liukoiset sokerit. Eri kehitysvaiheissa korjatusta materiaalista tehtiin myös tuhka- ja kivennäismäärityksiä.

Ohran olki

Ohranäytteet otettiin vuosina 2005 ja 2006 Jokioisten kartanoiden ohraviljelyksistä, joissa lajikkeena oli Artturi-rehuohra. Näyteala (40 m x 50 m) jaettiin viiteen kerranteeseen ja kukin lohko vielä kuuteen ruutuun (kuusi näytteenottokertaa ohran eri kasvuvaiheissa). Lohkon sisällä ruudut arvottiin eri näytteenottokertoja varten. Kussakin ohran kasvuvaiheessa lohkoilta (5) leikattiin maan pintaa myöten ohrasta yhden neliön näytealalta kaksi näytettä, kukin kooltaan 0,5 m x $1 \mathrm{~m}$. Kummankin näytteen tuorepaino punnittiin. Toinen näyte silputtiin ja siitä määritettiin kuiva-ainepitoisuus. Toinen näyte kuivattiin alle $+40{ }^{\circ} \mathrm{C}$ lämpötilassa tasokuivurissa kokonaisena, varastoitiin paperisäkissä, ja siitä määritettiin ohran satokomponentit (olki, lehdet, tähkä/jyvät) ja kemiallinen koostumus. Ohran kasvua ja oljen laadun kehitystä seurattiin eri kehitysvaiheissa (tarkat näytteenottopäivämäärät taulukossa 2):

1. Kesäkuun loppu (noin $20 \%$ ohrista tähkällä)

2. Heinäkuun alku (ohra täydellä tähkällä)

3. $\quad$ Keskikesä

4. Heinäkuun loppupuolisko (ohra maito-/taikinatuleentunut)

5. $\quad$ Elokuun alku (ohra keltatuleentunut)

6. Elokuun keskivaihe (kasvusto leikkuupuintivalmis)

Ennen laatuanalyysejä tähkä ja olki erotettiin mahdollisuuksien mukaan toisistaan. Ensimmäisessä näytteenotossa tähkä oli osassa näytettä vielä piilossa lehtitupen sisässä. Vaikka keskikesä 2006 oli kuiva, se ei näkynyt sadossa, koska ohran kasvupaikka oli hikevä eikä ohra kärsinyt vedenpuutteesta.

\section{Kemialliset määritykset}

Kemiallisia määrityksiä varten kasvinäytteet kuivattiin alle $+40^{\circ} \mathrm{C}$ lämpötilassa ja jauhettiin, seulakoko $<1 \mathrm{~mm}$. Kuitumääritykset tehtiin Tecator Fibertec System M -laitteistolla soveltaen van Soestin rehuanalyyseissä käytettyä detergenttikuitumenetelmää (AOAC 1990, Forage Analyses Procedures, 1993). Kasviraaka-aineesta määritettiin NDF (neutraali detergenttikuitu, solunseinämäaineksen kokonaismäärä), ADF (happodetergenttikuitu), joka sisältää selluloosan ja ligniinin sekä ADL (happodetergenttiligniini), joka jää jäljelle rikkihappouuton jälkeen. Materiaalin liukoiset sokerit määritettiin HPLC:llä (NMKL,1993). Tuhka määritettiin gravimetrisesti ja pii käyttäen IPC:tä. Kemialliset määritykset tehtiin MTT:n Kemian laboratoriossa.

\section{Tulokset ja tulosten tarkastelu \\ Ruokohelpi}

Ruokohelpikasvusto on heterogeenisempaa kuin esimerkiksi ohrakasvusto, sillä siinä on samaan aikaan eri-ikäisiä versoja. Uusia versoja syntyy lähinnä kevätkesällä ja syksyllä. Kevätversoista noin kolmannes tekee kukinnon (röyhyn), joka yltää 1,75-2 m:n korkeuteen. Osa versoista jää kasvullisiksi, korkeintaan noin metrin mittaisiksi. Tämän vuoksi myös korjattavan biomassan laatu vaihtelee enemmän kuin esimerkiksi oljella.

Taulokossa 1 on esitetty ruokohelven biomassan ja laatukomponenttien hehtaarisatojen kehittyminen vuosina 2005-2007. Vuonna 2005 ruokohelven suurin biomassasato $\left(11 \pm 0,4 \mathrm{t}_{\mathrm{ka}} / \mathrm{ha}\right)$ saatiin ruokohelven siemenen kypsyttyä (Taulukko 1, kehitysvaihe 4). Koska seuraavassa näytteenotossa 16.11. sadon määrä oli vain 7,5 $\mathrm{t}_{\mathrm{ka}}$ /ha, päätettiin vuonna 2006 tutkia tarkemmin ruokohelven myöhäisiä syyssatoja. Seuraavana vuonna suurin sato $\left(11 \pm 0,5 t_{k a} / h a\right)$ saatiinkin noin kuukausi siemenen kypsymisestä, minkä jälkeen sadot selvästi pienenivät. Ensimmäisen korjuuvuoden jälkeen vuosittain korjattavat kevätsadot yleensä suurenevat kasvuston vanhetessa. Lisäksi kasvusto säilyy kauemmin tuottokunnossa keväällä korjattaessa (Pahkala et al., 2005). Tässä tutkimuksessa koe järjestettiin molempina vuosina eri pakoissa, joten sadon em. kehitystä ei ollut mahdollista todeta.

Tutkimuksessa oli tärkeätä tietää, paljonko eri aineita saataisiin hehtaarilta. Tämän vuoksi myös kasvien koostumus on ilmoitettu hehtaarisatoina, jotka laskettiin pitoisuuden ja biomassasadon avulla (Taulukko 1). Vuonna 2006 selluloosan suhteellinen osuus sadossa lisääntyi kevääseen saakka, jolloin pitoisuus oli 47,7 $\pm 1,1 \%$ kuiva-aineesta (kehitysvaihe 9). Lokakuun näytteenotosta (kehitysvaihe 7, 
pitoisuus 44,9\%) lähtien muutokset selluloosapitoisuudessa eivät kuitenkaan olleet tilastollisesti merkitseviä. Hemiselluloosa- ja ligniini-pitoisuudet olivat suurempia myöhäissyksyllä ja kevätsadossa kuin aikaisemmissa näytteenotoissa. Kokeessa 703 kevätsadon hemiselluloosapitoisuus vaihteli välillä 25,1 -

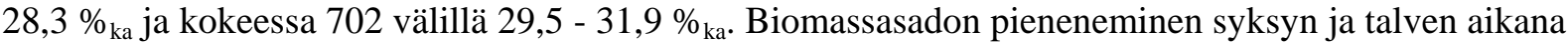
vaikutti vain vähän kuitukomponenttien hehtaarisaantoon.

Taulukko 1. Ruokohelven kuiva-ainesato sekä selluloosan, hemiselluloosan, ligniinin, tuhkan, sokerien (glukoosi, fruktoosi ja sakkaroosi) ja piin määrä (kg $\mathrm{kg}_{\mathrm{k}} / \mathrm{ha}$ ) eri kehitysvaiheissa vuosina 2005/2006 ja 2006/2007.

\begin{tabular}{|c|c|c|c|c|c|c|c|c|c|c|}
\hline $\begin{array}{l}\text { Kehitys- } \\
\text { vaihe }\end{array}$ & $\begin{array}{l}\text { Korjuu- } \\
\text { päivä }\end{array}$ & $\begin{array}{c}\text { Bio- } \\
\text { massa } \\
\text { kg/ha }{ }^{a}\end{array}$ & $\begin{array}{l}\text { Sellu- } \\
\text { loosa }\end{array}$ & $\begin{array}{l}\text { Hemi- } \\
\text { sellu- } \\
\text { loosa }\end{array}$ & $\begin{array}{l}\text { Lignii- } \\
\text { ni }\end{array}$ & Tuhka & $\begin{array}{l}\text { Glu- } \\
\text { koosi }\end{array}$ & $\begin{array}{l}\text { Fruk- } \\
\text { toosi }\end{array}$ & $\begin{array}{c}\text { Sakka- } \\
\text { roosi }\end{array}$ & Pii \\
\hline \multicolumn{11}{|c|}{ Koe 703 2005/2006 } \\
\hline 1 & 22.6.05 & $5762 a$ & 2079 & 1415 & 243 & & 128 & 134 & 43 & \\
\hline 2 & 5.7 .05 & $7627 a$ & 3091 & 1861 & 486 & & 133 & 147 & 68 & \\
\hline 3 & 14.7.05 & $9894 b$ & 4054 & 2404 & 777 & & 218 & 250 & 100 & \\
\hline 4 & 3.8.05 & $11083 b$ & 4433 & 2546 & 934 & 778 & 214 & 280 & 256 & \\
\hline 7 & 16.11.05 & 7550a & 3269 & 2084 & 716 & 590 & 60 & 69 & 0 & \\
\hline 9 & 2.5.06 & 7510a & 3263 & 1885 & 699 & 864 & 26 & 10 & 0 & 276 \\
\hline \multicolumn{11}{|c|}{ Koe 703 2006/2007 } \\
\hline 1 & 22.6.06 & 6661a & & & & & & & & \\
\hline 2 & 5.7 .06 & 8151ab & & & & & & & & \\
\hline 3 & 19.7.06 & 9407bc & & & & & & & & \\
\hline 4 & 31.7 .06 & 9867bc & 3523 & 2319 & 737 & 708 & 216 & 284 & 261 & \\
\hline 5 & 30.8 .06 & $11084 c$ & 3888 & 2380 & 795 & 680 & 183 & 289 & 125 & \\
\hline 6 & 27.9.06 & 8914ac & 3581 & 1807 & 813 & 568 & 195 & 303 & 72 & \\
\hline 7 & 26.10 .06 & $8476 a$ & 3808 & 2134 & 852 & 492 & 131 & 202 & 0 & \\
\hline 8 & 11.12 .06 & $7260 a$ & 3295 & 2042 & 699 & 425 & 47 & 46 & 0 & 151 \\
\hline 9 & 4.4.07 & $5762 a$ & 2746 & 1628 & 563 & 322 & 23 & 8 & 0 & 101 \\
\hline \multicolumn{11}{|c|}{ Koe $702 \quad 2005 / 2006$} \\
\hline 4 & 3.8.05 & 8205a & 3094 & 2154 & 521 & & 177 & 230 & 70 & \\
\hline 7 & 17.11.05 & 6665a & 2647 & 2043 & 553 & & 67 & 84 & 0 & \\
\hline 9 & 2.5.06 & $4165 b$ & 1700 & 1326 & 382 & 251 & 18 & 9 & 0 & 98 \\
\hline \multicolumn{11}{|c|}{ Koe $702 \quad 2006 / 2007$} \\
\hline 4 & 31.7.06 & $7707 a$ & & & & & & & & \\
\hline 7 & 26.10 .06 & $5605 b$ & & & & & & & & \\
\hline 9 & 4.4.07 & $4154 c$ & 1822 & 1225 & 364 & 224 & 22 & 22 & 0 & 80 \\
\hline
\end{tabular}

a) Keskiarvojen tilastollisesti merkitsevät erot on testattu Tukey-Kramer testillä ja merkitty eri kirjaimin.

Liukoisten sokerien yhteismäärä kiloina oli suurin heinä-elokuun vaihteessa siemenen kypsyttyä (600-700 kg/ha) ja alkoi sen jälkeen pienentyä. Sakkaroosia ei tavattu enää myöhäissyksyn eikä kevään näytteissä. Tuhkapitoisuus ei suuresti muuttunut kasvukauden aikana. Aikaisempien tutkimusten mukaan kevätsadon tuhkapitoisuus on pienempi kuin vihreänä korjattujen kasvien (Pahkala \& Miettinen, 2000). Myös tässä tutkimuksessa saatiin vastaavia tuloksia vuonna 2006. Kevätnäytteissä 2.5.2006 (kehitysvaihe 9/2005) havaittu poikkeuksellisen suuri tuhkapitoisuus (11,5 \%) johtui mahdollisesti Loimijoen tulvavedestä, joka virtasi keväällä 2006 kokeen yli tuoden mukanaan irtonaista maa-ainesta. Piin määrä alkuaineena mitattuna oli keväällä korjatussa materiaalissa 2,36 \% vuonna 2006 ja 1,93 \% vuonna 2007 (koe 702). Kokeessa 703 vastaavat luvut olivat 3,68 ja 1,75 \%. Kasveissa pii on silikaattina, jonka määrä saadaan kertomalla piipitoisuudet luvulla 2,1394.

Biomassan kuiva-ainepitoisuus vaihteli kesän ja syksyn aikana välillä 17 - 50 \%. Sään vaikutus kuiva-ainepitoisuuteen oli suuri. Keväällä biomassan kuiva-ainepitoisuus oli 84 - 91 \%. Kesän ja syksyn aikana korjatun biomassan kosteus oli niin suuri, että sitä ei olisi voitu varastoida kuivaamatta. Keväällä korjattu biomassa oli sellaisenaan varastointikelpoista.

Ohran olki

Taulukossa 2 on esitetty ohran kokonaissadon, olkisadon ja oljen laatutekijöiden kehitys kesän aikana. 
Koko kasvuston (tähkä, olki ja lehdet) yhteenlaskettu hehtaarisato kasvoi aina heinäkuun loppuun/elokuun

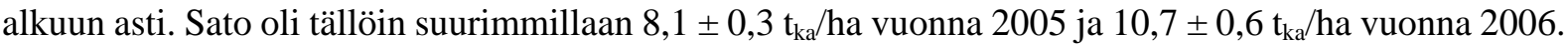
Kokonaissadon kasvu toisen näytteenoton (täysi tähkintä) jälkeen johtui yksinomaan tähkänpainon (jyvien) kasvusta. Tähkinnästä keltatuleentumiseen mennessä biomassasato kasvoi yli kaksinkertaiseksi. Vastaavasti olkisato hieman pieneni, koska ohra käyttää korteen ennen tähkintää tilapäisesti varastoituneet yhteyttämistuotteet jyväsadon kasvattamiseen. Tähkän (jyvät+vihneet+tähkälapakko) osuus kokonaissadoista oli vuonna 2005 noin 64 ja vuonna 2006 noin $69 \%$. Oljesta oli selluloosaa, hemiselluloosaa ja ligniiniä noin 48, 25 ja 7 \% vuonna 2005, sekä vuonna 2006 vastaavasti noin 44, 25 ja 8 \%. Kahden viimeisen näytteenoton välillä kasvuston hehtaarisato pieneni noin $10 \%$. Tämä johtuu lähinnä kasvuston hengityksestä ja lehtien varisemisesta. Oljen kosteusprosentti oli vuoden 2006 näytteissä nro 5 ja 6 noin 37 ja $21 \%$.

Taulukossa 2 on esitetty myös oljen eri laatukomponenttien hehtaarisatojen kehittyminen kesän aikana. Tulokset osoittavat, että oljen kannalta merkittävin kasvuvaihe on alkukesä ennen ohran tähkälletuloa. Koko kasvuston biomassa kasvoi tähkinnän jälkeen ainakin vielä kuukauden, kun jyvät kasvoivat varastoivat tärkkelystä ja valkuaisaineita. Vuoden 2005 olkisadossa ligniinin määrä lisääntyi ja tuhkan määrä väheni ohran kasvun myötä. Vuonna 2006 ligniinin ja tuhkan määrä ei juuri muuttunut ennen sadonkorjuuta. Piin (Si) pitoisuus tuleentuneessa oljessa oli 10,3 mg/kg ka (vuonna 2006). Oljen liukoisten sokerien (glukoosi, fruktoosi, sakkaroosi, fruktaanit) määrä väheni nopeasti ohran tähkälle tulon jälkeen, kun jyvät alkoivat kasvaa ja varastoida yhteyttämistuotteita.

Taulukko 2. Ohran korjuu eri kehitysvaiheissa vuosina 2005 ja 2006. Kokonaissato, olkisato ja selluloosan, hemiselluloosan, ligniinin, tuhkan, sokerien (glukoosi, fruktoosi ja sakkaroosi) ja piin määrä eri kehitysvaiheissa kg/ha kuiva-ainetta. Tuhka ja sokerit (glukoosi, fruktoosi, sakkaroosi) kg/ha.

\begin{tabular}{|c|c|c|c|c|c|c|c|c|c|c|}
\hline $\begin{array}{l}\text { Kehitys- } \\
\text { vaihe }\end{array}$ & $\begin{array}{c}\text { Korjuu- } \\
\text { päivä }\end{array}$ & $\begin{array}{l}\text { Ohran } \\
\text { bio- } \\
\text { massa }^{\text {a }}\end{array}$ & $\begin{array}{c}\text { Ohran } \\
\text { olki + } \\
\text { lehti } \\
\text { massa }^{\text {a }}\end{array}$ & $\begin{array}{l}\text { Sellu } \\
\text { loosa }\end{array}$ & $\begin{array}{l}\text { Hemi- } \\
\text { sellu- } \\
\text { loosa }\end{array}$ & $\begin{array}{l}\text { Lignii- } \\
\text { ni }\end{array}$ & Tuhka & $\begin{array}{l}\text { Glu- } \\
\text { koosi }\end{array}$ & $\begin{array}{l}\text { Fruk- } \\
\text { toosi }\end{array}$ & $\begin{array}{c}\text { Sakka- } \\
\text { roosi }\end{array}$ \\
\hline & 2005 & & & & & & & & & \\
\hline 1 & 27.6. & $3696 b$ & $2825 b$ & 869 & 533 & 113 & 247 & 88 & 105 & 165 \\
\hline 2 & 4.7. & $4650 \mathrm{~b}$ & $3340 a$ & 1129 & 557 & 141 & 252 & 100 & 145 & 238 \\
\hline 3 & 18.7. & $7466 a$ & 2927ab & 1193 & 601 & 192 & 206 & 49 & 109 & 67 \\
\hline 4 & 26.7. & $8104 a$ & $2505 b c$ & 1141 & 634 & 178 & 148 & 22 & 28 & 0 \\
\hline 5 & 1.8 . & $7656 a$ & $2228 c$ & 1071 & 553 & 163 & 134 & 10 & 0 & 0 \\
\hline 6 & $\begin{array}{r}8.8 \\
2006\end{array}$ & 7696a & $2174 c$ & 1112 & 515 & 174 & 104 & 10 & 0 & 0 \\
\hline 3 & 12.7. & 6966b & $3641 a$ & 1215 & 688 & 253 & 273 & 146 & 233 & 249 \\
\hline 4 & 20.7 . & 8862ab & $3344 a$ & 1279 & 661 & 245 & 266 & 88 & 166 & 140 \\
\hline 5 & 1.8. & 10720a & $3274 a$ & 1443 & 825 & 254 & 287 & 22 & 35 & 0 \\
\hline 6 & 7.8. & $9851 \mathrm{a}$ & 2995a & 1321 & 756 & 218 & 271 & 14 & 22 & 0 \\
\hline
\end{tabular}

${ }^{\mathrm{a}}$ ) Keskiarvojen tilastollisesti merkitsevät erot on testattu Tukey-Kramer testillä ja merkitty eri kirjaimin.

Kesällä 2006 tutkittiin näytteen 6 (leikkuupuintivalmis ohra) avulla myös oljen eri osien massaa ja sängen pituuden vaikutusta olkisaantoon (Taulukko 3). Tuloksista nähdään, että olki on tyveltä kosteampi, mutta myös tiheämpi. Jos sängen pituudeksi jätetään sadonkorjuussa esim. $15 \mathrm{~cm}$, menetetään noin $27 \%$ potentiaalisesta olkisadosta. Ohran puinnin yhteydessä mitattiin leikkuupuimurista tulleen oljen määrä ja ohran sängen pituus. Lohkojen ( $5 \mathrm{kpl}$ ) keskimääräinen sängenpituus oli $8,5 \mathrm{~cm}$ ja olkisato 2,8 $\mathrm{t}_{\mathrm{ka}}$ /ha. Tämä oli noin 10 prosenttia vähemmän kuin näytteenottoon perustunut potentiaalinen olkisato ja melko lähellä taulukon 3 arvoa. 
Taulukko 3. Oljen osien kuivapaino ja osuus koko oljesta. Ohran oljen jaottelu $5 \mathrm{~cm}$ pituisiin osiin. Näytteen koko on 50 ohrayksilöä ja tulokset ovat 5 toiston keskiarvoja. Jokioinen, 2006.

\begin{tabular}{c|ccccc}
\hline $\begin{array}{c}\text { Olkinäyte } \\
\text { cm }\end{array}$ & $\begin{array}{c}\text { Näytteen } \\
\text { kuiva- } \\
\text { paino, g }\end{array}$ & $\begin{array}{c}\text { Näytteen paino- } \\
\text { osuus koko } \\
\text { oljesta, } \%\end{array}$ & $\begin{array}{c}\text { Kumulatiivinen } \\
\text { paino-osuus koko } \\
\text { oljesta, \% }\end{array}$ & $\begin{array}{c}\text { Näytteen kuiva- } \\
\text { ainepitoisuus, \% }\end{array}$ & $\begin{array}{c}\text { Näytteen kuiva- } \\
\text { paino/cm } \\
\text { olkea }\end{array}$ \\
\hline $65-$ & 2,96 & 6,5 & 100,0 & 89,7 & 0,59 \\
$60-65$ & 2,35 & 5,1 & 93,5 & 87,1 & 0,47 \\
$55-60$ & 2,39 & 5,2 & 88,4 & 83,5 & 0,48 \\
$50-55$ & 3,09 & 6,8 & 83,2 & 77,3 & 0,62 \\
$45-50$ & 2,98 & 6,5 & 76,4 & 70,2 & 0,60 \\
$40-45$ & 3,08 & 6,7 & 69,9 & 64,8 & 0,62 \\
$35-40$ & 3,11 & 6,8 & 63,2 & 60,5 & 0,62 \\
$30-35$ & 3,08 & 6,7 & 56,4 & 55,9 & 0,66 \\
$25-30$ & 3,32 & 7,3 & 49,6 & 52,3 & 0,70 \\
$20-25$ & 3,49 & 7,6 & 42,4 & 50,9 & 0,71 \\
$15-20$ & 3,53 & 7,7 & 34,7 & 50,3 & 0,77 \\
$10-15$ & 3,83 & 8,4 & 27,0 & 48,3 & 0,81 \\
$5-10$ & 4,04 & 8,8 & 18,6 & 46,2 & 0,90 \\
$0-5$ & 4,48 & 9,8 & 9,8 & 45,2 & \\
\hline
\end{tabular}

\section{Johtopäätökset}

Ruokohelven suurin biomassasato saadaan alkusyksystä, jolloin saadaan myös liukoisista sokereista kilomääräisesti suurin sato, noin 600 - $700 \mathrm{~kg} / \mathrm{ha}$. Selluloosan saanto on suurin siemenen kehittymisen aikoihin elokuussa. Ruokohelven kevätsato on ensimmäisenä korjuuvuonna pienempi kuin syyskesällä korjattu sato, mutta sen kuiva-ainepitoisuus on korkea, mikä helpottaa varastointia. Tässä tutkimuksessa etanolin valmistukseen päädyttiin käyttämään siemenvaiheessa ja keväällä korjattua ruokohelpimateriaalia, jotka olivat prosessoitaessa lähes samanarvoisia.

Bioetanolituoton kannalta viljan olkisadon voisi korjata talteen jo keskikesällä, kun oljen hiilihydraattien (selluloosa ja liukoiset sokerit) määrä on suurimmillaan, mutta tuolloin korjatun ohran versominen ja jälkikasvu jää hyvin vähäiseksi. Tämän vuoksi tässä tutkimuksessa päädyttiin yhteen oljen korjuuaikaan, joka tapahtuisi normaalin leikkuupuinnin yhteydessä. Tällöin olkea voi ympäristön kannalta käsitellä sivuvirtana. Viljakasvien olkisato ei myöskään ole kovin suuri verrattuna esimerkiksi ruokohelven biomassasatoon. Sängenpituus vaikuttaa huomattavasti olkisatoon.

\section{Kirjallisuus}

AOAC 1990. Fiber (Acid detergent) and lignin in animal feed. (973.18). Official methods of analysis. Association of Official Analytical Chemists. $15^{\text {th }}$ edition.

Mäkinen, T., Soimakallio, S., Paappanen, T., Pahkala, K. \& Mikkola, H. 2006. Liikenteen biopolttoaineiden ja peltoenergian kasvihuonekaasutaseet ja uudet liiketoimintakonseptit. VTT tiedotteita 2357. http://virtual.vtt.fi/inf/pdf/tiedotteet/2006/T2357.pdf

NMKL. 1993. Nordic Committee on Food Analysis. Fructose, glucose and saccharose, NMKL publications 148, 4 p. Pahkala, K., Isolahti, M., Partala, A., Suokannas, A., Kirkkari, A.-M., Peltonen, M., Sahramaa, M., Lindh, T. Paappanen, T., Kallio, E. \& Flyktman, M. 2005. Ruokohelven viljely ja korjuu energian tuotantoa varten. 2. korjattu painos. Maa- ja elintarviketalous 1.31 p. http://www.mtt.fi/met/pdf/met1b.pdf

Pahkala, K. \& Miettinen, E. 2000. Ruokohelpilajikkeet kevätkorjuussa. In: Riitta Salo (toim.). Biomassan tuottaminen kuidun ja energian raaka-aineeksi. Tutkimuksen loppuraportti, osa I. Ruokohelven jalostus ja viljely. Maatalouden tutkimuskeskuksen julkaisuja. Sarja A 84. Jokioinen: Maatalouden tutkimuskeskus. p. 32-41.

Weymarn, N. von (toim). 2007. Bioetanolia maatalouden selluloosavirroista. VTT tiedotteita 2412. http://virtual.vtt.fi/inf/pdf/tiedotteet/2007/T2412.pdf 